\title{
Multi-Source Energy Harvesting Architecture With A Common Control Circuit
}

\author{
Ridvan UMAZ* \\ Bitlis Eren University, Electrical-Electronics Engineering, Bitlis
}

(ORCID: 0000-0003-3733-2327)

\begin{abstract}
Multiple source energy harvesting architecture with a common control circuit is presented in this paper. As multiple energy sources, thermoelectric generator (TEG), microbial fuel cell (MFC) and solar cell (PV) are deployed. With the proposed architecture, all sources allow to provide supply voltage to the load and self-starting i.e., no need of external power sources is achieved. Results are carried out in a $0.13 \mu \mathrm{m}$ CMOS process and show the effectiveness of the proposed architecture over the conventional converter circuits. The output is regulated to $1.58 \mathrm{~V}$.
\end{abstract}

Keywords: Power converter, Energy harvesting, Energy combining, TEG, MFC, Solar cell, wireless sensor networks.

\section{Bir Ortak Kontrol Devresi ile Çok Kaynaklı Enerji Hasadı Tasarımı}

\section{$\ddot{O} \mathbf{z}$}

Bu makalede ortak bir kontrol devresi ile çok kaynaklı enerji hasadı mimarisi sunulmaktadır. Çoklu enerji kaynağı olarak termoelektrik jeneratörü (TEG), mikrobiyal yakıt hücresi (MFC) ve güneş hücresi (PV) kullanılmıştır. Önerilen sistem ile tüm enerji kaynaklarının yüke voltaj sağlanması amaçlanmıştır. Sistemin başka bir güç kaynağına ihtiyaç duyulmaksızın kendi gücünü sağlanması gerçekleşmiştir. Bir $0.13 \mu \mathrm{m}$ CMOS teknolojisi kullanarak sonuçlar elde edilmiştir. Sonuçlar önerilen sistemin geleneksel güç devrelerinden daha etkili olduğunu gösterir. Çıkış voltajı $1.58 \mathrm{~V}$ olarak ayarlanmıştır.

Anahtar kelimeler: Güç dönüştürücü, enerji hasadı, enerjinin toplanması, yenilenebilir enerji kaynakları, kablosuz sensör ağları.

\section{Introduction}

Energy harvesting for autonomous systems has been enormously becoming a realistic approach to power up a wide set of applications such as portable electronic devices and wireless sensor networks (WSN) through their surrounding environment. Extracting energy from surrounding environment can be sunlight or artificial indoor light defined as solar cell energy, thermal gradient defined as thermoelectric generators (TEGs), electrochemical defined as microbial fuel cells (MFCs), and others which are not focused on this paper.

Energy harvesting from a single energy source may be neither sufficient to power up a specific load (i.e., specifically heavy loads e.g., hydrophone which are required more energy than generated energy by energy sources.) nor even to lead to the perpetual lifetime of the load. Multi-source energy harvesting system combining can be considered to increase both overall input power and the energetic reliability and functionality of the system [1-8].

\footnotetext{
"Sorumlu yazar: rumaz@beu.edu.tr

Geliş Tarihi: 13.03.2019, Kabul Tarihi: 23.07.2019
} 


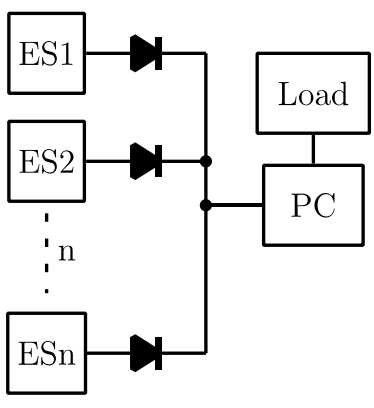

a)

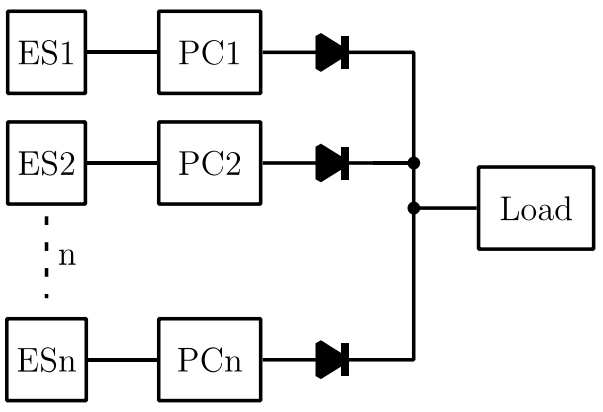

b)



c)

Figure 1. (a) A block diagram of an input based power-ORing connected to a common node through diodes. (b) A block diagram of an output based power-ORing. (c) Proposed multiple energy sources combiner.

Previous approaches for multiple energy sources have been discussed throughout literature. Works in $[1,6,7]$ aimed to achieve energy combining for multiple energy sources by simply merging the outputs of multiple energy sources to a common node directly or through a switch, so called input based power-ORing, as shown in Figure 1(a). This common node provides energy supply to a power converter (PC) to up convert the output voltage at the required level by the load. Simply combining the outputs of multiple energy sources to directly a common node can cause degradation at the overall efficiencies. This is mainly due to the fact that the overall efficiency is constrained by the highest generated voltage, but the lower generated voltages are not utilized at their best efficiencies i.e. excluded the lower generated voltage contributions. However, combining for multiple energy sources to a common node through a switch (e.g., a diode) requires a high start-up voltage (e.g., greater than voltage of $1 \mathrm{~V}$.) due to voltage drop over diode. Providing the minimum required start-up voltage by each energy source may not achieve since each energy source generates low voltages at their outputs (e.g., TEGs, typically generated voltage less than $100 \mathrm{mV}$ ).

Another approach for combining multiple energy sources is to connect them through their power converters (PCs) [6], so-called output based power-ORing, as shown in Figure 1(b). This approach achieves the best performance over input based power-ORings i.e., eliminates voltage drop over diodes at the outputs of energy sources and includes all energy sources to contribute powering the load. Although this work effectively operates for some low voltage energy sources (e.g. solar cells and MFCs), it is not well-dedicated design for ultra-low voltage energy sources. In other words, generated voltage at the output of the source is less than threshold voltage of deployed CMOS technology in the design (e.g., for TEGs, typically less than $100 \mathrm{mV}$ ). Thus, the power converter cannot start operating and the energy source contribution on the load is excluded.

However, there is a need for a more convenient energy harvesting architecture for multiple energy sources combiner. In this paper, some key challenges over conventional designs should be achieved: 1) whole system should be self-start up without depending any pre-charge or battery voltage, especially start-up issue for ultra-low voltage generated energy source such as thermoelectric generators (TEGs); 2) a wide input voltage range operation should be allowed for multiple energy sources; 3 ) switching frequency of each converter associated with energy sources should be synchronized for remarkable maximum energy extraction point; finally, energy harvesting from each individual sources should be concurrently proceeded.

A multiple energy sources energy harvesting architecture with a common control circuit is presented in this paper. The overall design of the proposed circuit is shown in Figure 1(c). At the top level, the circuit consists of power converters for each energy source and a common control circuit (CCC), which generates signals for switching power converters. 


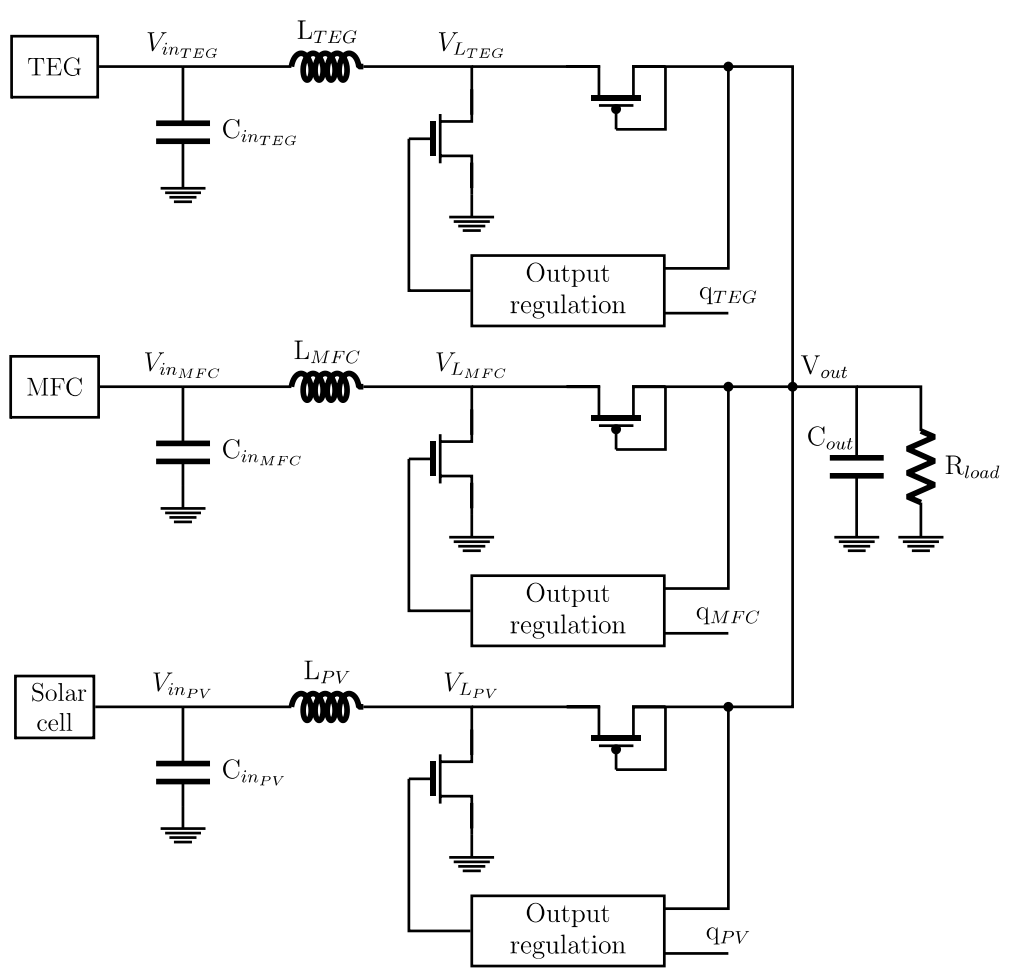

(a)



(b)

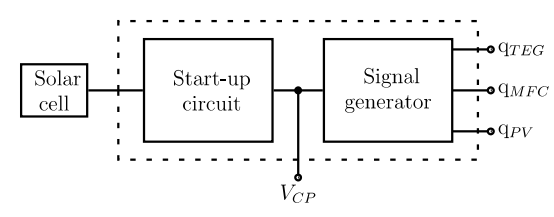

(c)

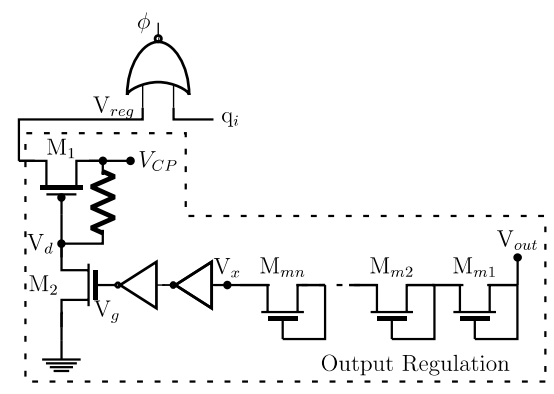

(d)

Figure 2. (a) Proposed multi-source energy harvesting architecture, (b) Thevenin equivalent circuit for solar cell and electrical equivalent circuit model for TEGs and MFCs, (c) Block diagram of the start-up and signal generator which is referred to common control circuit (CCC), (d) Output regulation circuit.

\section{The Proposed Multi-Source Energy Harvesting Architecture}

The proposed architecture of the multi-source energy harvesting is shown in Figure 2(a). Each energy source is connected to the load through their power converters, which are based on switching inductor converter. While inputs of the proposed architecture are varied due to deployed different kind of energy sources (i.e., Solar cell, TEG and MFC), their outputs are merged to the same point to feed the heavy loads, which require more energy than single energy source generated.

Although our proposed architecture for multiple energy sources is structured as the output based power-ORing (see Figure 1(b)), each converter switching frequency generates from the common control circuit (qi) i.e. have a common control signal generator. Basically, switching frequency of each converter is independent from each energy source voltage at their outputs $\mathrm{V}_{\mathrm{in}}$ due to obtaining them from common control circuit (CCC). One energy source whose voltage at its output is higher than others are used as power supply for start-up circuit to kick-start all system and assist signal generator generate control signal for each converter. Note that selection of energy source for supplying start-up circuit can be any source whose generated voltage at their outputs are higher than the threshold voltage of CMOS transistor are used in the design.

Each converter has its own output regulation circuit which is locked roughly the output voltage level of $1.58 \mathrm{~V}$. In what follows, the detailed design of the proposed architecture of the multi-source energy harvesting and maximum power extraction from each source will be described.

\subsection{Maximum Power Extraction}

The thevenin equivalent circuit for any energy harvesting source can be modeled as a voltage source VS in series with a resistor RS, as shown in Figure 2(b). Generally, some energy sources (e.g. TEGs and MFCs) electrical equivalent circuits are modeled as seen in Figure 2(b). Maximum power extraction is 
obtained once the resistance of RS is equal to the resistance of connected gadget (e.g. converters, loads, charge pumps) $\mathrm{Z}_{\mathrm{L}}$, this is referred to impedance matching theory. The maximum power can be obtained from any energy source through thevenin circuit shown in Figure 2(b) can be given by

$$
P_{\max }=\frac{V_{S}^{2}}{4 R_{S}}=\frac{V_{S}^{2}}{4 Z_{L}}
$$

Once the switching frequency for the converter is designed to be two times of $q_{i}$ to accomplish the maximum power, the converter input impedance can be given by

$$
Z_{L}=8 L f
$$

The input power of the converter from the output of the energy source can be given by

$$
P_{C}=\left(\frac{V_{S}}{R_{S}+Z_{L}}\right)^{2} \times Z_{L}=\left(\frac{V_{S}}{R_{S}+8 L f}\right)^{2} \times 8 L f,
$$

Matching efficiency $\eta_{M}$ can be viewed as the ratio of $P_{C}$ to $P_{\max }$ is given by

$$
\eta_{M}=\frac{P_{C}}{P_{\max }}=\frac{4}{\frac{8 L f}{R_{S}}+\frac{R_{S}}{8 L f}+2},
$$

More than 90\% matching efficiency (6) i.e. maximum extracted power from energy source can be available once ratio of $\mathrm{Lf} / \mathrm{RS}$ is kept in the condition presented in (5). In the design, the internal impedance of energy source RS and inductor of the converter L are generally constant, but optimal frequency can be tuned up/down for maximum power extraction from energy sources.

$$
\begin{aligned}
& 0.065 \leq \frac{L f}{R_{S}} \leq 0.2375, \\
& 90 \% \leq \eta_{M} \leq 100 \%,
\end{aligned}
$$

\subsection{Common Control Circuit (CCC)}

Generated low voltage at the output of the energy source definitely affects either the overall efficiency or the proper functionality of the power converter due to the generated voltage very close to the threshold voltage of CMOS transistor. Therefore, it is an essential need for design a start-up circuit to step up the low output voltage from the source to a value higher than the threshold voltage of the CMOS transistors (e.g. $130 \mathrm{~nm}$ feature size in this paper). A two stages charge pump is employed as a start-up circuit in this paper.

Even though some energy harvesting systems can have their own start-up circuits, ultra-low energy source (e.g. TEGs) whose voltage at the output is much lower than the threshold voltage of the CMOS transistor cannot have its one. Some start-up mechanisms for individual implemented TEGs have been discussed $[10,11]$. However, these start-up concepts are not an efficient way to apply to multisource energy harvesting systems because of either not self-starting or difficulty in implementation.

It is not necessary for each source to have their special start-up circuits in the multi-source energy harvesting architecture. One common start-up circuit can cater for a variety of different energy sources. Thus, we have one common start-up circuit whose operations start from the output of selected energy source $V_{\text {in }}$ to boosts its output to $\mathrm{V}_{\mathrm{CP}}$, as shown in Figure 2(c). Energy source as a supply voltage for start-up circuit is deter- mined by which one of the generated voltages at the outputs of the sources is much far away from the threshold voltage of the CMOS transistors. This process can be formulated as 


$$
V_{i n}=M A X\left\lfloor V_{i n_{T E G}}, V_{i n_{M F C}}, V_{i n_{P V}}\right\rfloor,
$$

Note that solar cell in this paper is selected energy source for start-up circuit. After energy supply issue for control circuit in multi-source energy harvesting system are solved, the control circuit generates switching cycle to control on/off status power MOSFETs in the converter i.e. 50\% duty cycle squarewave are formed to allow inductor $\mathrm{L}$ to charge from the input of the converter and discharge to the output of the converter.

In this paper, one common control circuit is used with synchronized signal generation for each other in terms of maximum power extraction mentioned in Sec. 2.1. The signal generations for TEG, MFC and solar cell to switch inductor frequency for each energy source are 8X, X and 2X, respectively. Over $90 \%$ matching efficiencies are fulfilled for multi- source energy harvesting in this paper by keeping switching frequencies in these ratios (see eq. (5)).

\subsection{Output Regulation}

The output voltage regulation circuit is shown in Figure 2(d) including the gate-drain connected transistors and a NOR gate. To keep the output voltage at the desired level, the gate-drain connected transistor schemes is utilized as dropping voltage across the transistors. The voltage at the source of the $\mathrm{M}_{\mathrm{mn}}$ transistor, $\mathrm{V}_{\mathrm{X}}$, is given by

$$
V_{x}=V_{\text {out }}-n \times V_{g s}
$$

When $V_{X}$ exceeds the inverter pull down transistor threshold voltage $V_{t h n}$ (i.e. $V_{g 1} \geq V_{t h n}$ ), the voltage at $\mathrm{V}_{\mathrm{g}}$ goes high to facilitate M2 conducting. The gate voltage $\mathrm{V}_{\mathrm{d}}$ of the PMOS transistor M1 drops to zero, since the drain of M2 is connected to ground. The resistor acts as a linear element to supply current to the gate of the M1 transistor. The M1 transistor conducts and sends the signal to the input of the NOR gate.

Substituting $\mathrm{V}_{\mathrm{X}}=\mathrm{V}_{\text {thn }}$ into (8), the output voltage at the boost converter is given by

$$
V_{\text {out }}=n \times V_{g s}+V_{t h n}
$$

Note that inverters are used to enable switching quickly, not causing delay or inappropriate transitions at $\mathrm{V}_{\mathrm{g}}$.

\section{Results}

The proposed multi-source energy harvesting architecture was evaluated in HSPICE using a $0.13 \mu \mathrm{m}$ CMOS process. The architecture has been tested with three energy sources; TEG, MFC and solar cell. A $40 \mathrm{mV}, 400 \mathrm{mV}$ and $500 \mathrm{mV}$ input voltage source was used to emulate TEG, MFC and solar cell, respectively. The power converter (i.e., PCi) uses a $20 \mu \mathrm{H}$ inductor (i.e., LTEG=LMFC=LPV) and a 14.7 $\mu \mathrm{F}$ output capacitor $\mathrm{C}_{\text {out }}$. As the load, a resistance of $1 \mathrm{k} \Omega$ is utilized for demonstration purposes. 

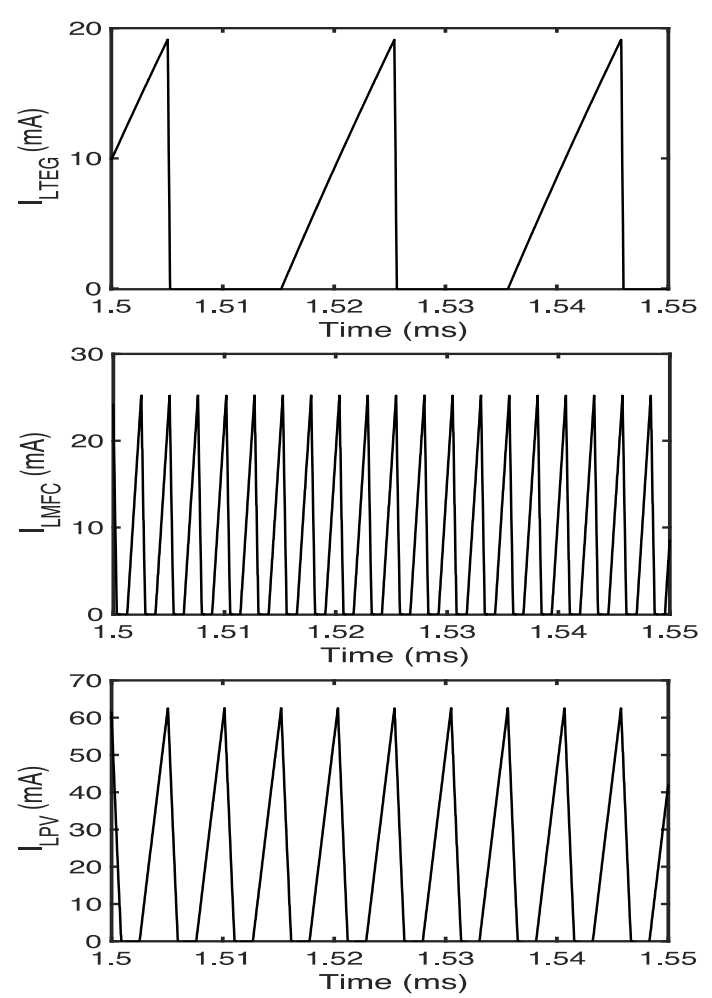

a)
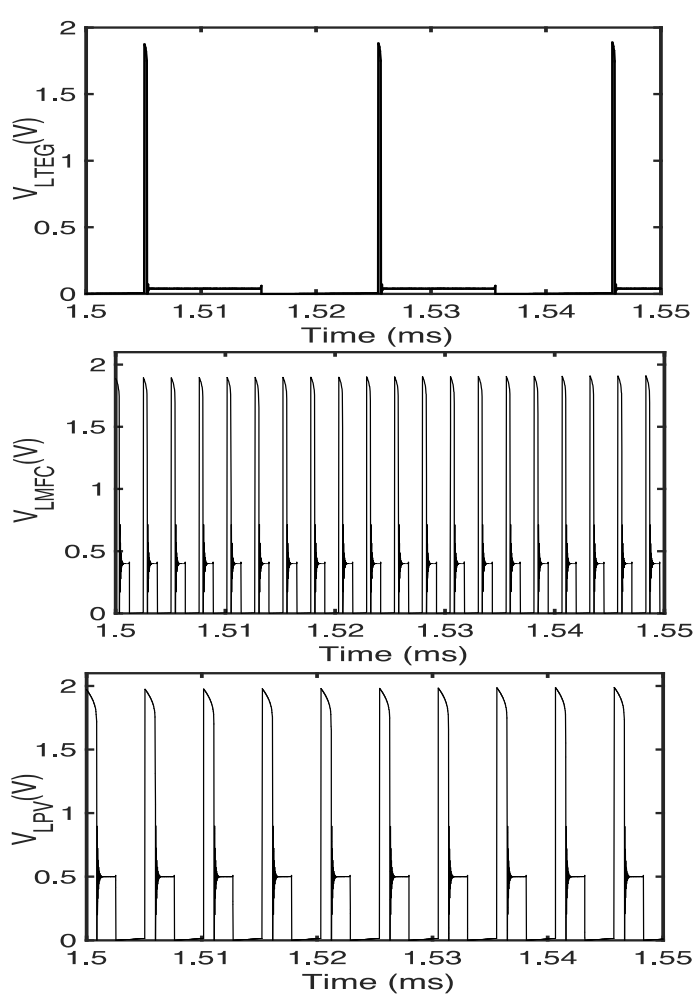

b)

Figure 3. (a) Currents at inductors LTEG, LMFC and LPV, (b) Voltage waveforms at VLTEG, VLMFC and VLPV.

Figure 3 shows currents through inductors (i.e., LTEG, LMFC and LPV and voltages at VLTEG, VLMFC and VLPV at a specific time interval. It can be seen that each energy source has different switching times. This is mainly due to the fact that the common control circuit generates different switching frequencies for each source. It can be seen that the power converter designed for MFC has more switching cycles than others since the converter has the lowest switching frequency. The maximum currents for TEG, MFC and solar cell (PV) are roughly $19 \mathrm{~mA}, 24 \mathrm{~mA}$ and $61 \mathrm{~mA}$, respectively. It can be seen from Figure 3(a) currents are not allowed to flow negatively due to the implementation of the discontinuous conduction mode converter in the proposed architecture. Voltages at inductors VLTEG, VLMFC and VLPV are nearly $1.85 \mathrm{~V}, 1.9 \mathrm{~V}$ and $2 \mathrm{~V}$.

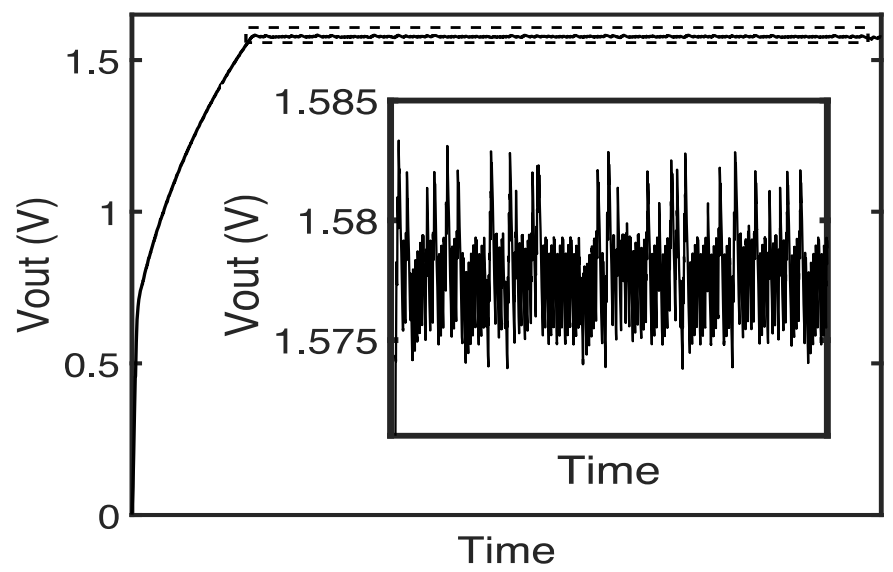

Figure 4. The output voltage of the proposed architecture. Inset zooms in area shown at the dashed rectangular.

Figure 4 shows the output voltage of the proposed architecture. Three energy sources provide supply power to the load. Initially, the output of the architecture $\mathrm{V}_{\text {out }}$ is low and not reached the steady state. The output capacitor $\mathrm{C}_{\text {out }}$ is charged by energy sources through power converters PC1-PC2. Once 
the capacitor voltage reaches the steady state, the output voltage $\mathrm{V}_{\text {out }}$ is regulated to $1.58 \mathrm{~V}$ by the output regulation circuit in Figure 2(d). The inset figure zooms in the dashed rectangular of Figure 4 in order to show that the output regulation circuit works properly.

In order to indicate the contribution of all sources (e.g., TEG, MFC and PV) to the load, the current at the output capacitor $\mathrm{C}_{\text {out }}$ is monitored, as shown in Figure 5. Once the inductor $\mathrm{L}_{\mathrm{i}}$ starts discharging to $\mathrm{C}_{\text {out }}$ through PMOS transistor, $\mathrm{C}_{\text {out }}$ starts to charge i.e., the current flowing into the output capacitor. Then the load starts flowing out the current from the output capacitor i.e., the capacitor starts discharging. It can be seen from Figure 5 that all inductors start discharging to the load since switching frequencies for all inductors are overlapped (see Figure 3(a)). The maximum current at $\mathrm{C}_{\text {out }}$ is the sum of maximum currents at ITEG-PV and is given by

$$
I_{\text {cout }_{\max }}=I_{L T E G_{\max }}+I_{L M F C_{\max }}+I_{L P V_{\max }}
$$

Once all energy sources contribute to the load (see in Figure 5 with a red color, TEG+MFC+PV), the current at $\mathrm{C}_{\text {out }}$ is at $104 \mathrm{~mA}$, which is expected value from eq. 10 (see in Figure 3(a) ILTEG $_{\max }=19 \mathrm{~mA}, I_{L M F C} \max =24 \mathrm{~mA}, \mathrm{ILPV}_{\max }=61 \mathrm{~mA}$ ). Once two energy sources (e.g., MFC and $\mathrm{PV}$ ) provide supply power to the load i.e., their switching frequencies are overlapped; the current at $\mathrm{C}_{\text {out }}$ is at $85 \mathrm{~mA}$ (see in Figure 5 with a blue color, MFC+PV). Only one energy source (e.g., MFC) powers up the load through its power converter, the inductor current at LMFC is transferred to Cout which is at nearly $24 \mathrm{~mA}$ (see in Figure 5 with a green color, MFC). This result points out that the proposed architecture includes all energy sources contributions to the load with a common control circuit and works properly.

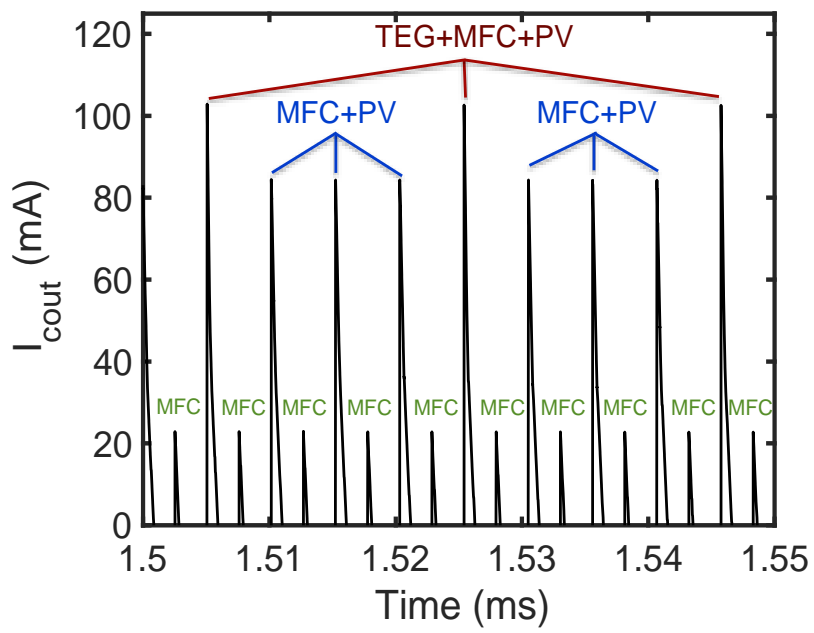

Figure 5. Current at the output capacitor $\mathrm{C}_{\text {out }}$. Red color shows all sources contributions TEG+MFC+PV. Blue color two sources MFC+PV contributions. Green color one source MFC contribution.

\section{Conclusion}

This paper presents a multi-source energy harvesting architecture with a common control circuit. Multiple energy sources are used to power up the load. The maximum power extraction from energy sources is achieved. The start-up issue for ultra-low voltage energy source (e.g., TEGs) is solved doing by employing a common control circuit to generate signals for power MOSFETs. The output of the architecture is regulated to $1.58 \mathrm{~V}$ by output regulation circuits. Results indicate the effectiveness of the proposed architecture over the existing works; allowing all energy sources to contribute to the load and self-start up. 


\section{References}

[1] Carli D., Brunelli D., Benini L., Ruggeri M. 2011. An effective multisource energy harvester for low power applications, Proc. Design, Automation \& Test in Europe (DATE), pp. 1-6.

[2] Qian F., Umaz R., Gong Y., Li B., Wang L. 2016. Design of a shared-stage charge pump circuit for multi-anode microbial fuel cells, IEEE International Symposium on Circuits and Systems (ISCAS), pp. 213-216.

[3] Shi C., Miller B., Mayaram K., Fiez T. 2011. A multiple-input boost converter for low-power energy harvesting, IEEE Trans. Circuits Syst. II Exp. Briefs, 58 (12): 827-831.

[4] Umaz R., Garett C., Qian F., Li B., Wang L. 2017. A power management system for multi-anode benthic microbial fuel cells, IEEE Trans. on Power Electronics, 32 (5): 3562-3570.

[5] Bandyopadhyay S., Chandrakasan A.P. 2012. Platform architecture for solar thermal and vibration energy combining with MPPT and single inductor, IEEE J. Solid-State Circuits, 47 (9): 2199-2215.

[6] Colomer-Farrarons J., Miribal-Catala P. Siz-Vela A., Samitier J. 2011. A Multi harvested selfpowered system in a low-voltage low-power technology, EEE Trans. Ind. Electronics, 58 (9): 4250-4263.

[7] Tan Y.K., Panda S.K. 2011. Energy harvesting from hybrid indoor ambient light and thermal energy sources for enhanced performance of wireless sensor nodes, IEEE Trans. Ind. Electronics, 58 (9): 4424-4435.

[8] Umaz R., Wang L. 2017. An Energy Combiner Design for Multiple Microbial Energy Harvesting Sources, In Proceedings of the on Great Lakes Symposium on VLSI 2017 (GLSVLSI '17), pp. 443-446.

[9] Lhermet H., Condemine C., Plissonier M., Salot R., Audebert P., Rosset M. 2008. Efficient power management circuit: From thermal energy harvesting to above-IC micro battery energy storage, IEEE J. Solid State Circuits, 43 (1): 246-255.

[10] Ramadass Y.K., Chandrakasan A.P. 2011. A battery-less thermoelectric energy harvesting interface circuit with $35 \mathrm{mV}$ startup voltage, IEEE J. Solid State Circuits, 46 (1): 333-341.

[11] Carlson E., Strunz K., Otis B. P. 2010. A $20 \mathrm{mV}$ input boost converter with efficient digital control for thermoelectric energy harvesting, IEEE J. Solid State Circuits, 45 (4): 741-750. 